\title{
Pharmacologic Therapy in Postpartum Pelvic Pain Management
}

\author{
ALEXANDRA MATEI ${ }^{1 \#}$, CRINGU IONESCU2, MIHAI DIMITRIU2*, CORINA ILINCA ${ }^{3}$, DIANA GHEORGHIU1\#, MIHAI BANACU2, \\ DAN CALIN², LIANA PLES', ADRIAN NEACSU', GEORGE ROSU ${ }^{1}$ \\ ${ }^{1}$ St Pantelimon Clinical Emergency Hospital, Department Obstetrics Gynecology, 340 Pantelimon Road, 021661, Bucharest, \\ Romania \\ ${ }^{2}$ Carol Davila University of Medecine and Pharmacy, Department Obstetrics Gynecology and Neonatology, 37 Dionisie Lupu Str, \\ 020021, Bucharest, Romania. \\ 3University of Bucharest, Faculty of Sociology and Social Work and Statistical Office, 4-12 Regina Elisabeta Blvd, 030018, \\ Bucharest, Romania \\ ${ }^{4}$ Dunarea de J os University of Galati, 47 Domneasca Str, 800008, Galati, Romania
}

\begin{abstract}
Women's perception on childbirth experience is frequently related to pain struggle, regardless the type of birth. We aimed to present our Department's experience on pharmacologically treating postpartum related pain. We developed a 6 months retrospective, descriptive study which included a number of 305 patients. Two sample patients were formed depending on the type of birth. In the sample of vaginal delivery a correlation between episiotomy and Paracetamol consumption was found (Pearson correlation of 0.238). In the sample of cesarean section births, for Acupan, Ketoprofen and Algifen the correlations with epidural anesthesia are negative and statistically significant at the $99.9 \%$ confidence level.
\end{abstract}

Keywords: analgesia, postpartum pain, episiotomy, epidural anesthesia

Women's perception on childbirth experience is frequently related to pain struggle, regardless the type of birth. Pain intensity, pain-related disability, pain duration and pain aûect are the aspects that deûne pain and its effects [1]. Although the first three can be easily assessed using various instruments, pain affect defined as the degree of emotional arousal or changes in action readiness caused by the sensory experience of pain [2] is often more difficult to objectify.

Pain can be perceived differently especially under the specific neurohormonal changes characterizing immediate postnatal period. The direct effects on the mother's wellbeing and her ability to care for her infant are strong aspects that influence initiation of specific therapy. Postpartum depression affects 1 in 7 mothers [3]. The negative impact on the patient's psychological health sometimes resulting in maternal suicide has brought this pathology into specialist's attention once more. Even if it is still underdiagnosed in many healthcare systems and neglected by the medical research field, evidence suggests that an association exists among acute postpartum pain, chronic pain and postpartum depression $[4,5]$.

Whether it is related to the pelvic trauma of vaginal birth or to the surgical scar after caesarean section, pain under all its forms remains the major most common symptom to treat after delivery. American College of Obstetricians and Gynaecologists states that nonpharmacologic and pharmacologic therapies are important components of postpartum pain management [6]. It is known that pain is multifactorial, therefore multimodal analgesia is the best approach [7]. It uses drugs that have differentmechanisms of action which potentiates the analgesic effect [6]. Depending on the intensity and the subjective complaints regarding pain experience, patients are usually given analgesics following a stepwise approach. Step one includes nonopioid analgesics (eg, acetaminophen or nonsteroidal anti-inflammatory drugs - NSAID), step two adds milder opioids (eg, codeine, hydrocodone, oxycodone, tramadol, oral morphine), and step three incorporates stronger opioids (eg, parenteral morphine, hydromorphone, fentanyl) [6].
We aimed to present our Department's experience on pharmacologically treating postpartum related pain by analysing all medical records on patients who delivered in our clinic between December 2017 and May 2018. We focused especially on the use of the following commercial pharmacological products: Paracetamol (acetaminophen), Acupan (nefopam hydrochloride), Algifen (metamizole, pitofenone hydrochloride and fenpiverinium bromide) and Ketoprofen (propionic acid derivate).

\section{Experimental part}

We developed a 6 months retrospective, descriptive study which included a number of 305 patients who delivered in our Department.

Inclusion criteria were based on the informed consent of the patient to take part in this study along with admission for delivery in St. Pantelimon Emergency Hospital during December 2017 to May 2018. Patients who gave written refusal to follow any prescribed therapy on the medical chart were excluded from this study. Women diagnosed with postnatal complications such as infections, haemorrhage or haematomas were not considered.

All data was gathered from each patient's electronic medical record stored in Info World application as well as from their admission papers.

We considered being relevant the entire therapeutical plan of patients during their hospitalization after delivery, with focus on the administration of the following pharmacological commercial products: number of Paracetamol vials along with Ketoprofen, Algifen and Acupan ampoules.

Other drugs destined to treat comorbidities were not taken into account. Also, we did not evaluate the opioid drug use because in our department Mialgin-the only compound used from this class - is administered scarcely.

This analysis is based on descriptive statistics (number of cases, percentages, mean, standard deviation, minimum and maximum) and correlational analysis (providing Pearson correlations and the statistical significance level). We used IBM SPSS Statistics, version 22. 
The variables included in the analysis are the following: number of vials or ampoules of the pharmacological compounds used, length of hospital stay in days, presence or absence of episiotomy and epidural anesthesia. The variables were analyzed in two samples: one including patients who delivered vaginally and the other including women who delivered by cesarean section.

The results of this study are influenced by a few significant drawbacks: there weren't any pain objectifying instruments like visual analogue scales applied to the patient before pain treatment nor in the evaluation of pain reduction. Data collection is appointed as a possible source of bias.

\section{Results and discussions}

\section{Descriptive statistics}

This study comprises a number of 305 patients aged 14 to 42 years old ( 26.9 years old in average). We found that 92 patients ( $30.1 \%$ ) delivered vaginally and had 14 to 42 years old ( 25.2 years in average), while 213 patients $(69.9 \%)$ delivered by cesarean section and had between 15 and 41 years old (28.6 years in average) (fig. 1)

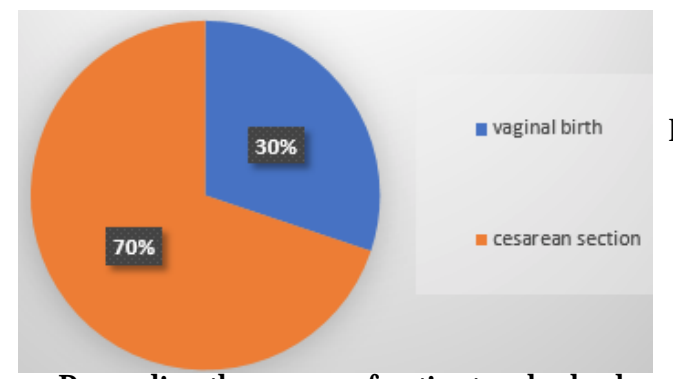

Fig. 1. Types of birth in the sample group here

Regarding the group of patients who had vaginal delivery, 50 patients (54.3\%) out of 92 were primiparas; 91 were single pregnancies and 1 was a twin pregnancy; 13 patients (14.1\%) had premature birth and corresponding gestational

\begin{tabular}{|c|c|c|c|c|c|}
\hline & $\%$ & Mean & S.D. & Min. & Mas \\
\hline Paracetamol & & & & & \\
\hline $\begin{array}{l}\text { Vaginal delivery } \\
\qquad(\mathbb{N})\end{array}$ & 92 & 1.57 & 1.29 & 0 & 5 \\
\hline $\begin{array}{r}\text { Cesarean delivery } \\
(N)\end{array}$ & & 1.38 & 0.97 & 0 & 3 \\
\hline $\begin{array}{l}\text { Ketoprofen } \\
\text { Vaginal delivery } \\
\begin{array}{ll} & \\
& (N)\end{array}\end{array}$ & 92 & 2.99 & 1.33 & 0 & 6 \\
\hline $\begin{array}{l}\text { Cesarean delivery } \\
\text { Algifen }\end{array}$ & 213 & 4.18 & 1.10 & 2 & 8 \\
\hline & 92 & 3.51 & 1.35 & 0 & 6 \\
\hline $\begin{array}{r}\text { Cesarean delivery } \\
(\mathbb{N})\end{array}$ & 213 & 4.54 & 1.01 & 3 & 7 \\
\hline Acupan & & & & & \\
\hline $\begin{array}{r}\text { Vaginal delivery } \\
\qquad(\mathrm{N})\end{array}$ & 92 & 3.45 & 1.57 & 0 & 6 \\
\hline $\begin{array}{r}\text { Cesarean delivery } \\
(\mathrm{N})\end{array}$ & 213 & 5.27 & 1.42 & 3 & 8 \\
\hline $\begin{array}{l}\text { Length of hospital stay } \\
\text { Vaginal delivery } \\
\begin{array}{ll}\text { (N) }\end{array}\end{array}$ & 92 & 3.34 & 0.56 & 2 & 5 \\
\hline $\begin{array}{r}\text { Cesarean delivery } \\
(\mathrm{N})\end{array}$ & 213 & 4.20 & 0.67 & 3 & 6 \\
\hline $\begin{aligned} \text { Episiotomy } & \text { Vaginal de } \\
0 . & \text { No } \\
1 . & \text { Yes } \\
& \text { (N) }\end{aligned}$ & $\begin{array}{l}\text { livery) } \\
19.6 \\
80.4 \\
92\end{array}$ & & & & \\
\hline $\begin{aligned} & \text { Epidural anesthesia (C } \\
& 0 . \text { No } \\
& 1 . \text { Yes } \\
&(\mathrm{N}) \\
&\end{aligned}$ & $\begin{array}{l}\text { sarean del } \\
31.5 \\
68.5 \\
213 \\
\end{array}$ & ery) & & & \\
\hline
\end{tabular}

age between 29 weeks 0 days and 36 weeks 6 days. 79 patients (85.8\%) delivered at term (37weeks 0 days and above) Infants born from mothers in this group weighted between $1980 \mathrm{~g}$ and $4150 \mathrm{~g}$ ( $3209.3 \mathrm{~g}$ in average). Seventy four (74) patients (80.4\%) had episiotomy/episiorraphy. Patients were hospitalized 3.3 days on average.

The group of patients who delivered by cesarean section had 102 primiparas (47.8\%). There were 3 multiple pregnancies (twin pregnancies). Twenty three (23 or 10.7\%) were premature births (corresponding gestational age between 29 weeks 0 days and 36 weeks 6 days) and 190 $(89.2 \%)$ were at term (37weeks 0 days and above). Newborns delivered in this group had between $1350 \mathrm{~g}$ and $4200 \mathrm{~g}$ (3449.1g in average). A number of 146 patients $(68.5 \%)$ had peridural anesthesia. Patients were hospitalized 4.2 days on average.

Analgesic consumption (table 1) of Paracetamol is similar for both types of delivery, with a mean of 1.57 vials for vaginal delivery and 1.38 vials for cesarean delivery. The maximum values are different, for vaginal delivery we have a maximum of 5 Paracetamol vials and for cesarean delivery a maximum of 3 vials. Ketoprofen consumption has a mean value of 2.99 ampoules for vaginal delivery (with a range between 0 and 6 ampoules) and a mean value of 4.18 ampoules for cesarean delivery (with a range between 2 and 8 ampoules). Algifen consumption is a bit different as well, with a mean of 3.51 ampoules for vaginal delivery (ranging between 0 and 6 ampoules) and a mean value of 4.54 ampoules of cesarean delivery (ranging between 3 and 7 ampoules). The difference is wider for Acupan consumption, with a higher mean for cesarean delivery (5.27 ampoules; minimum 3 ampoules and maximum 8 ampoules), for vaginal delivery having a mean of 3.45 (minimum 0 ampoules and maximum 6 ampoules).
Table 1 DESCRIPTIVE STATISTICS 
Women with cesarean delivery stay longer in the hospital, on average (a mean of 4.20 days, with a minimum of 3 days and a maximum of 6 days), compared to women who delivered vaginally, who stay a mean of 3.34 days (minimum 2 days and maximum 5 days). Eight out of ten women with vaginal delivery had an episiotomy and 7 out of 10 women with cesarean delivery had epidural anesthesia (table 1).

\section{Correlations}

For women with vaginal delivery, correlations between episiotomy and analgesic consumption (table 2) show a statistically significant result at the $95 \%$ confidence level only for the correlation between episiotomy and Paracetamol consumption (Pearson correlation of 0.238). Thus, women with episiotomy had more Paracetamol vials than women without episiotomy. For the other analgesics, the level of consumption is similar for women with and without episiotomy.

Table 2

CORRELATIONS BETWEEN EPISIOTOMY AND ANALGESIC CONSUMPTION (SAMPLE: W OMEN WITH VAGINAL DELIVERY)

\begin{tabular}{|c|c|c|}
\hline & Pearson correlation & Sig \\
\hline Ipisiotomy $*$ Paracetamol & 0.238 & $=0.05$ \\
\hline Episiotomy * Ketoprcfen & -0.004 & - \\
\hline Epixiotomy $*$ Nlgifen & 0.187 & - \\
\hline Episiotomy * Acupan & 0.123 & - \\
\hline
\end{tabular}
consumption in the sample of women with cesarean delivery (table 3), we found that only the correlation between epidural anesthesia and Paracetamol consumption is not statistically significant, meaning that there is no variation in the second variable when the first one changes its value. For all the others, the correlations are negative and statistically significant at the $99.9 \%$ confidence level. Thus, women with epidural anesthesia are less likely to be prescribed Ketoprofen ampoules as well as any Algifen or Acupan doses (Pearson correlations: $-0.586,-0.612$ and -0.556 respectively).

All correlations between length of hospital stay and analgesic consumption are not statistically significant at any accepted level (for both samples, with vaginal or

Table 3

CORRELATIONS BETWEEN EPIDURAL ANESTHESIA AND ANALGESIC CONSUMPTION (SAMPLE: WOMEN WITH CAESARIANE DELIVERY)

\begin{tabular}{|c|c|c|}
\hline & \multicolumn{2}{|c|}{ Pearson correlation } \\
\hline Epidural * Paracetemol & -0.065 & - \\
\hline Epidural * Ketoprofen & -0.586 & $=0.001$ \\
\hline Epidural * Algifen & -0.612 & $=0.001$ \\
\hline Epidural $*$ Acupan & -0.556 & $<0.001$ \\
\hline
\end{tabular}

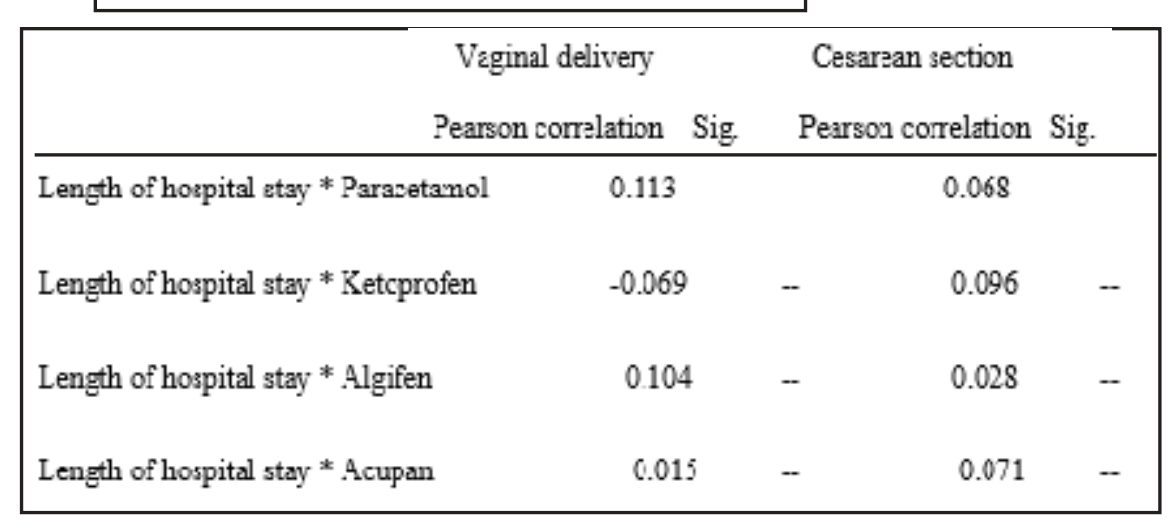

cesarean delivery), showing that women who stay longer in hospital have similar levels of analgesic consumption with women who stay shorter periods of time in hospital. Based on these samples, we cannot say that the longer women stay in hospital, the higher their analgesic consumption, at least based on our bivariate analysis (table 4). Hospitalization is most certain influenced by other medical factors like the patient's comorbidities and is sometimes determined by the newborn's status and his need for medical care.

Pain as a symptom often translates an ongoing inflammatory process in a certain situs in the body. The most common sources of pain in the first days after vaginal birth are breast engorgement, uterine contractions, and perineal lacerations [6]; we also add the episiotomy scar as an important factor, since in our study $80.4 \%$ of the patients underwent this minor intervention. We did not focus on any other source of pain except the pelvic area; perineal lacerations were not mentioned, possibly biased by data collection process. The latest recommendations regarding analgesia after vaginal birth, mention that oral drug administration is preferred. In this report, all the 4 pharmacological compounds were administered by intravenous or by intramuscular injection. American College of Obstetricians and Gynaecologists state that for uterine cramping Nonsteroidal anti-inflammatory medications are more effective than acetaminophen [6].

Paracetamol (acetaminophen/N-(4-hydroxyphenyl) acetamide), a drug used for its analgesic and antipyretic activity, is known to be the main metabolite of phenacetin formed in vivo [8]; it does not possess any antiinflammatory property and therefore is prescribed to be administered in single therapy or combined with other medication. In our study we evaluated the use of intravenous infusion only. It was prescribed for short term administration in mild pain and/or fever. A single vial of Paracetamol is prepared under $10 \mathrm{mg} / \mathrm{ml}$ formula.

A 2016 systematic review concluded that NSAIDs appear to be more effective than acetaminophen at 4 hours after birth (relative risk, 1.54; $95 \% \mathrm{Cl}, 1.07-2.22$ ), but there is no significant difference at 6 hours after birth [9]. However, the results of our study underline the fact that women with episiotomy had more Paracetamol vials than women without episiotomy while the consumption of other analgetics was similar.

Lately, the focus has been set on single dose therapy effectiveness and studies have shown that a single dose of acetaminophen (500-1.000 mg) or an NSAID relieves pain better than placebo $[9,10]$.

Concerning the patients who underwent caesarean section, it has been proven that neuraxial opioids provide the greatest postcesarean birth analgesia, but most women require additional analgesia because the effects of neuraxial opioids diminish [11]. For instance, Acupan, Ketoprofen and Algifen are the most used analgesics in our department and multimodal therapies are implemented for each patient in the immediate postoperative period.

\section{Table 4}

CORRELATIONS BETWEEN ANALGESIC CONSUMPTION AND LENGTH OF HOSPITAL STAY (SAMPLES: WOMEN WITH VAGINAL DELIVERY AND WOMEN WITH CAESARIANE OPERATION) 
Acupan is an injectable drug, one ampoule of $2 \mathrm{ml}$ containing $20 \mathrm{mg}$ of nefopam hydrochloride (5-methyl-1phenyl-1,3,4,6-tetrahydro-2,5-benzoxazocine hydrochloride). It is known to be a centrally-acting, nonopioid benzoxazocine with analgesic activity [12]. It can be administered by intramuscular injection or by slow intravenous infusion especially for postop pain [13]. The mechanism of action of nefopam hydrochloride is unclear [12] but may involve inhibition of serotonin, dopamine and noradrenaline reuptake.

Algifen is a pharmaceutical compound containing metamizole (sodium [(1,5-dimethyl-3-oxo-2-phenylpyrazol-4-yl)-methylamino] methanesulfonate), pitofenone hydrochloride (methyl 2-[4-(2-piperidin-1-ylethoxy) benzoyl] benzoate hydrochloride) and fenpiverinium bromide (4-(1-methylpiperidin-1-ium-1-yl)-2,2-diphenylbutanamide bromide). This product is retailed in $5 \mathrm{ml}$ ampoules. Metamizole is a drug that has analgesic, antiinflammatory, antipyretic and spasmolytic properties [14] The analgesic effect is based on the inhibition of a central cyclooxygenase-3 and activation of the opioidergic system and cannabinoid system, while the mechanism responsible for the spasmolytic effect is associated with the inhibited release of intracellular Calcium as a result of the reduced synthesis of inositol phosphate [15]. Along with two antispasmodic agents: pitofenone hydrochloride and fenpiverinium bromide, Metamizole forms an effective analgesic and parasympatholytic mixture prescribed for intense acute pain syndrome following surgery.

Ketoprofen (2-(3-benzoylphenyl)propanoic acid) is a propionic acid derivate and nonsteroidal antiinflammatory drug with anti-inflammatory, analgesic and antipyretic effects; this drug inhibits the activity of the enzymes cyclo-oxygenase $I$ and II, resulting in a decreased formation of precursors of prostaglandins and thromboxanes [16], this way explaining especially its antiinflammatory effect. An ampoule of Ketoprofen contains a drug distribution of $100 \mathrm{mg} / 2 \mathrm{ml}$.

In our study we have proven that women with epidural anesthesia are less likely to be prescribed Ketoprofen ampoules as well as any Algifen or Acupan doses.

Surely, postoperative oral administration of analgesics has also been studied and results showed that paracetamol $1000 \mathrm{mg}$ and $650 \mathrm{mg}$ had a number-needed-to-treat of 4.6 (3.8-5.4) and 5.3 (4.1-7.2) respectively for at least $50 \%$ pain relief when compared with placebo [17]. An interesting perspective for our department to use would be the use of ocal anesthetics delivered by wound infiltration or transversus abdominis plane block [11, 18, 19].

Another point reached in our study mentions the hospitalization period. Even if a correlation has been sought between the length of stay and the need for pain therapy, no statistical relationship could be established between these variables because adjustments involving other maternal and fetal factors were compulsory to make. Ahlen proved that in Sweden hospital length of stay was longer for caesarean section delivery (emergency and elective) compared to vaginal delivery $(p<0.01)[20]$. However, beside the delivery mode, it is essential to take into consideration the existence of maternal comorbidities along with possible postpartum complications like haemorrhage and infections when discussing hospitalization. At the same time, a sensitive aspect regarding iatrogeny is currently set out to explore, particularly since microbial contamination of biomaterials in medical practice has become a main concern in the last two decades [21].

Postpartum depression as a result of unsatisfactory pain management has been a subject of debate over the last years; preliminary results are inconclusive but a novel hypothesis suggests that the woman's experience of pain control after labor is likely to contribute more to the evolution of depression [22-30]. We take into consideration the possibility of discovering future connections between different stages of the birth process and the patient's perception on pain experience.

\section{Conclusions}

Paracetamol is the preferred administered analgesic in patients who had episiotomy during vaginal birth.

Among patients who delivered by cesarean section, in those with epidural anesthesia the pharmacological regimen of pain was significantly reduced compared to those without epidural anesthesia.

Multiple maternal and newborn related factors are compulsory to consider along with maternal analgesic regimen when analysing the hospitalization length.

\section{References}

1.HAEFELI M, ELFERING A. Eur Spine J (2006) 15: p.17-24

2.VON KORFF M, JENSEN MP, KAROLY P. Spine (2000) 25: p. 3140-3151 3.WISNER KL, SIT DK, MCSHEA MC, et al. JAMA Psychiatry. 2013; 70: p.490-498

4.EISENACH JC, PAN PH, SMILEY R, LAVAND'HOMME P, LANDAU R, HOULE TT. Pain. 2008; 140: p.87-94

5.DING T, WANG DX, QU Y, CHEN Q, ZHU SN. Anesth Analg. 2014; 119: p.383-392

6.*** ACOG Committee opinion Number 742. Committee on Obstetric Practice. Postpartum pain management.

7.LEUNG L. J Prim Health Care 2012; 4:p. 254-258.

8.MASHKOVSKII MD. Pharmaceutical Chemistry J ournal. Vol. 29, No. 7, 1995. Translated from Khimiko-Farmatsevticheskii Zhumal, Vol. 29, No. 7, p. 46 - 53, July, 1995

9.WUYTACK F, SMITH V, CLEARY BJ . Cochrane Database of Systematic Reviews 2016, Issue 7. Art. No.: CD011352

10.CHOU D, ABALOS E, GYTE GM, GGLMEZOGLU AM. Cochrane Database of Systematic Reviews 2013, Issue 1. Art. No.: CD008407

11.SUTTON CD, CARVALHO B. Anesthesiol Clin 2017; 35: p.107-124 12.***https://www.ncbi.nlm.nih.gov/mesh/68009340

13.***http://base-donnees-publique.medicaments.gouv.fr/ extrait.php?specid $=62580656$

14.***https://www.ncbi.nlm.nih.gov/mesh/68004177

15.J ASIECKA A, MASLANKA T, J AROSZEWSKI J. Pol J Vet Sci. 2014;17(1): p. 207-214.

16.*** https://ncit.nci.nih.gov/ncitbrowser ConceptReport. jsp?dictionary $=\mathrm{NCl}$ Thesaurus\&ns $=\mathrm{NCl}$ Thesaurus\&code $=\mathrm{C} 47578$ 17.MOORE A, COLLIINS S, CARROLL D, MCQUAY H, EDWARDS J. Cochrane Database Syst Rev. 2000; (2):CD001547

18.LAVAND'HOMME PM, ROELANTS F, WATERLOOS H, DE KOCK MF. Anesthesiology 2007; 106: p. 1220-1225.

19.ESLAMIAN L, JALILI Z, JAMAL A, MARSOOSI V, MOVAFEGH A. J Anesth 2012; 26: p.334-338.

20.AHLEN KM, ÖRTQVIST AK, GONG T et al. PLoS One. 2016 Oct 7;11(10):e0164126

21.TANASE G, BURLIBASA M, MUNTIANU L et al. METALURGIA INTERNATIONAL Vol 15 Special Issue: 2, 2010. p.160-162

22.LIM G, FARRELL LM, FACCO FL, GOLD MS, WASAN AD. Anesth Analg. 2018; 126: p.1598-1605.

23.POPESCU, E.,FORNA,D.A., EARAR,K.., et al., Mat. Plast., 54, no. 2, 2017, p.390-392

24.ASAFTEI,I.V., SANDU, I.G., BIRSA,L.M., et al.,Rev. Chim. (Bucharest), 66, no. 3, 2015,p. 336-341

25.J UMANCA,D.,GALUSCAN,A., PODARIU,A.C., et al., Rev. Chim. (Bucharest) 65, no. 12, 2014, p.336-341

26.LUNGU,M.,ROMILA, A., NECHITA,A., et.al., ACTA MEDICA MEDITERRANEA; 33(3), 2017, pg.369-376

27.GRIGORIU,R., CALIN,A.M., ARBUNE,M., et.al., Rev. Chim. (Bucharest), 67, no. 2), 2016, p.366-371

28. CALIN, A.D., ,PROCEEDINGS OF $201618^{\text {TH }}$ INTERNATIONAL SYMPOSIUM ON SYMBOLIC AND NUMERIC ALGORITHMS FOR SCIENTIFIC COMPUTING(SYNASC), 2016, PG.264-261

29.SALARU,D.L., Mertens,P.R., BARTSCH, P, INTERNATIONAL UROLOGY AND NEPHROLOGY,45(5), 2013, PG.248-250

30.SALARU,D.L., MACOVEI, L., STATESCU, C., et al., REVISTA ROMANA DE MEDICINA DE LABORATOR, 21(4),2013, PG.407-414 